\title{
ANALIZA DRGAŃ POPRZECZNYCH SMUKŁEJ KOLUMNY O ZMIENNYM PRZEKROJU POPRZECZNYM PRZY OBCIĄŻENIU UOGÓLNIONYM Z SIŁĄ SKIEROWANĄ DO BIEGUNA DODATNIEGO
}

\begin{abstract}
W pracy zawarto wyniki rozważań teoretycznych oraz analizę numeryczną zagadnienia drgań swobodnych smukłego układu o zmiennym przekroju poprzecznym poddanego działaniu wybranego przypadku obciążenia swoistego. Analizowane obciążenie uogólnione z siłą skierowaną do bieguna dodatniego realizowane jest poprzez strukturę zbudowaną z głowic z zarysie kołowym: wywołującą i przejmującą obciążenie. W celu zamodelowania niepryzmatyczności kolumny, układ podzielono na $n$ pryzmatycznych segmentów o równej długości i grubości oraz zmiennej szerokości opisanej za pomocą funkcji liniowej oraz wielomianu drugiego stopnia, przy zachowaniu warunku stałej objętości sumarycznej. W oparciu o model fizyczny układu zdefiniowano zależności określające energię mechaniczną struktury. Problem sformułowano na podstawie zasady Hamiltona (metoda drgań, kinetyczne kryterium utraty stateczności). Biorąc pod uwagę geometryczne warunki brzegowe oraz geometryczne warunki ciągłości wyznaczono różniczkowe równania ruchu poszczególnych segmentów kolumny oraz brakujące do opisu układu naturalne warunki brzegowe i naturalne warunki ciągłości. W oparciu o tak zdefiniowany model matematyczny opracowano autorskie algorytmy obliczeniowe umożliwiające badania numeryczne drgań poprzecznych układu. W ramach przeprowadzonych obliczeń określono zakres zmian częstości drgań własnych w funkcji obciążenia zewnętrznego. Dyskusji poddano wpływ zmiennych parametrów geometrycznych kolumny na wartość częstości drgań oraz typ układu, uwzględniając parametry określające kształt kolumny oraz geometrię struktury realizującej obciążenie.
\end{abstract}

Słowa kluczowe: układy smukłe, drgania swobodne, obciążenie swoiste, obciążenie krytyczne

\footnotetext{
1 Janusz Szmidla, Politechnika Częstochowska, Instytut Mechaniki i Podstaw Konstrukcji Maszyn, ul. J. H. Dąbrowskiego 73, 42-201 Częstochowa; tel. +48 (34) 32-50-616; szmidla@ @imipkm.pcz.pl

2 Autor do korespondencji / corresponding author: Anna Jurczyńska, Politechnika Częstochowska, Instytut Mechaniki i Podstaw Konstrukcji Maszyn, ul. J. H. Dąbrowskiego 73, 42-201 Częstochowa; tel. +48 (34) 32-50-683; a.jurczynska@imipkm.pcz.pl
} 


\section{Wprowadzenie}

Układy niepryzmatyczne są powszechnie stosowane w budowie maszyn i konstrukcjach mechanicznych. Ze względu na coraz to większe wymagania stawiane konstruktorom, poszukuje się optymalnych kształtów struktur, które zapewniać mają wzrost przenoszonego obciążenia lub redukcję ciężaru układu.

W zakresie dynamiki układów niepryzmatycznych analizie poddano drgania harmoniczne belki Bernoullego - Eulera o skokowo zmiennej sztywności na zginanie z elementami dyskretnymi [1]. Badaniom poddano wpływ zmiany przekroju poprzecznego oraz usytuowania zmian przekroju wzdłuż osi układu na utratę stateczności dynamicznej układu. Rozwiązanie zagadnienia stateczności i drgań swobodnych niepryzmatycznej kolumny przy obciążeniu eulerowskim przedstawiono $\mathrm{w}$ pracy [2]. Analizie poddano różne przypadki zamocowania układu. Wyznaczono wartości obciążenia krytycznego i częstości drgań własnych w zależności od kształtu kolumny. Zagadnienia drgań poprzecznych belki o skokowo zmiennym przekroju dotyczy również praca [3]. Wyniki dotyczące drgań swobodnych sprężyście zamocowanej kolumny Timoshenki uzyskane przy użyciu metody transformaty przedstawiono w pracy [4]. Analizę drgań kolumny o skokowo zmiennym przekroju poprzecznym z zamodelowaniem pęknięć w punktach zmiany przekroju układu (uskok) zaprezentowano w pracy [5]. Do sformułowania i rozwiązania zagadnienia wykorzystano własności funkcji Greena. W pracy [6] przedstawiono badania drgań poprzecznych niepryzmatycznej belki Timoshenki poddanej jednoczesnemu działaniu siły osiowej oraz stycznemu obciążeniu ciągłemu. Dokładne rozwiązanie otrzymanego układu równań rządzących uzyskano poprzez wyrażenie współczynników zredukowanego równania różniczkowego w postaci wielomianu a następnie zastosowanie metody Frobeniusa. Wyniki badań dotyczących stateczności kolumny Becka o zmiennej masie i sztywności z uwzględnieniem tłumienia otrzymane w oparciu o kompletną, nieliniową analizę dynamiczną przedstawiono w pracy [7]. Rozwiązanie nieliniowych różniczkowych równań ruchu o zmiennych współczynnikach opisujących dynamikę układu rozwiązano stosując metodę równań równoważnych (AEM) Katsikadelisa. Analiza drgań swobodnych wielosegmentowej belki Bernoullego - Eulera podpartej sprężyście na obu końcach była tematem pracy [8]. Wykazano, że zaproponowana metoda rozwiązania zagadnienia brzegowego - metoda rozkładu Adomiana - może być użyta do analizy drgań różnego typu belek niepryzmatycznych zbudowanych z dowolnej liczby członów.

Celem niniejszej pracy jest analiza numeryczna zagadnienia drgań swobodnych kolumny o zmiennym przekroju poprzecznym rozpatrywanej jako zbiór pryzmatycznych segmentów, realizującej obciążenie uogólnione z siłą skierowaną do bieguna dodatniego. 


\section{Model fizyczny układu}

W pracy rozważa się przedstawiony na rys. 1 smukły układ o zmiennym przekroju poprzecznym. W celu zamodelowania niepryzmatyczności kolumny, strukturę rozpatruje się jako zbiór $n$ pryzmatycznych segmentów o równej długości $l$ oraz grubości $h$. Zmienną szerokość poszczególnych segmentów opisano funkcją liniową $b(x)=2 a(Z) \cdot x+d$ oraz wielomianem drugiego stopnia $b(x)=2\left(a(p, q) \cdot[x-p]^{2}+q\right)$. W rozważaniach przyjęto warunek stałej sumarycznej objętości układu. Dodatkowo założono, że szerokość poszczególnych segmentów nie może być mniejsza od ich grubości $(b(x) \geq h)$.

a)

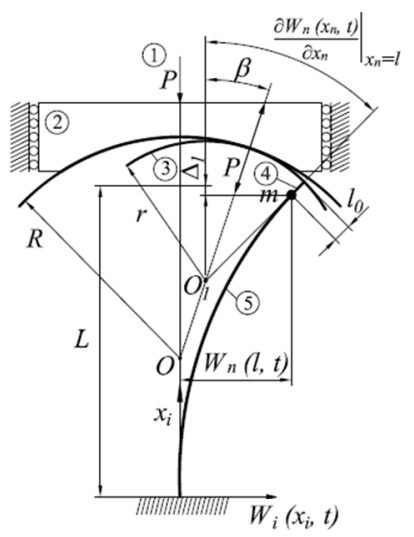

b)

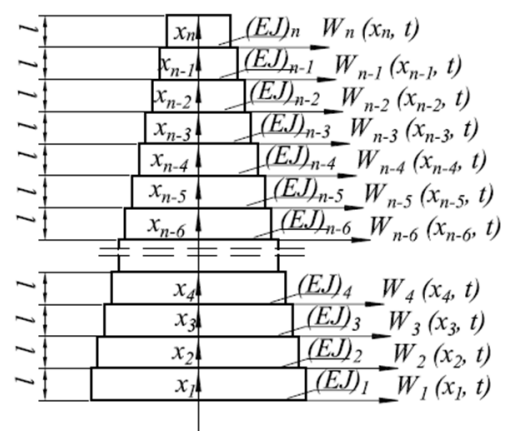

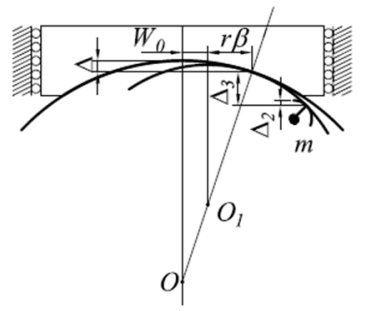

c)

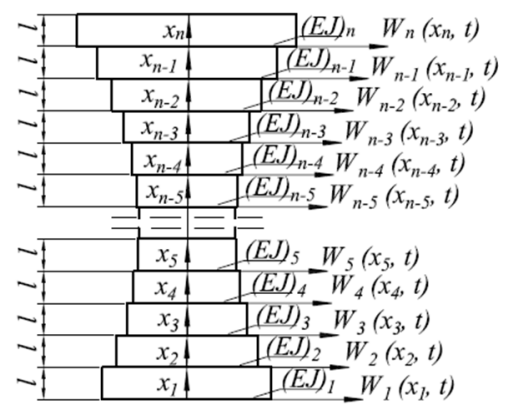

Rys. 1. Model fizyczny układu: a) schemat ogólny kolumny poddanej działaniu obciążenia uogólnionego z siłą skierowaną do bieguna dodatniego oraz geometria struktury obciążającej. Podział układu przy aproksymacji kształtu b) funkcją liniową c) wielomianem drugiego stopnia

Fig. 1. Physical model of the system: a) scheme of the column subjected to the generalized load with a force directed towards the positive pole and the geometry of the loading structure. The division of the system into segments when the shape is approximated by b) linear function c) polynomial of degree 2 
Obciążenie uogólnione z siłą skierowaną do bieguna dodatniego (przypadek obciążenia swoistego) realizowane jest poprzez strukturę zbudowaną z elementów o zarysie kołowym [9, 10]. Obciążenie zewnętrzne (1) przekazywane jest z głowicy wymuszającej (2) o promieniu $R$ na głowicę przejmującą obciążenie (3) o promieniu $r$ a następnie poprzez nieskończenie sztywny element o długości $l_{0}$ na kolumnę. Kierunek działania siły przechodzi przez punkt $O_{I}$ będący środkiem krzywizny głowicy przejmującej obciążenie oraz stały punkt $O$ znajdujący się na nieodkształconej osi układu poniżej swobodnego końca (biegun dodatni). Uwzględnienie w modelu elementu (4) uzasadnione jest względami konstrukcyjnymi. Masa skupiona $m$ uwzględnia całkowitą zredukowaną masę elementów składowych głowicy przejmującej obciążenie.

\section{Sformułowanie i rozwiązanie zagadnienia brzegowego}

Na podstawie zdefiniowanego $\mathrm{w}$ rozdziale 2. modelu fizycznego określono energię mechaniczną układu. Całkowita energia potencjalna $V$ jest sumą energii sprężystości zginania poszczególnych członów kolumny $V_{1}$ oraz energii wynikającej z obciążenia zewnętrznego $V_{2}$ :

$$
\begin{aligned}
& V_{1}=\frac{1}{2} \sum_{i=1}^{n}(E J)_{i} \int_{0}^{l}\left[\frac{\partial^{2} W_{i}\left(x_{i}, t\right)}{\partial x_{i}^{2}}\right]^{2} d x_{i} \\
& V_{2}=-P \Delta_{1}-P \Delta_{2}+P \Delta_{3}+\frac{1}{2} P \beta\left[W_{0}+r \beta\right]
\end{aligned}
$$

przy czym:

$$
\begin{aligned}
& \Delta_{1}=\frac{1}{2} \sum_{i=1}^{n} \int_{0}^{l}\left[\frac{\partial W_{i}\left(x_{i}, t\right)}{\partial x_{i}}\right]^{2} d x_{i}, \quad \Delta_{2}=\frac{1}{2} l_{0}\left[\left.\frac{\partial W_{n}\left(x_{n}, t\right)}{\partial x_{n}}\right|_{x_{n}=l}\right]^{2} \\
& \Delta_{3}=\frac{r}{2}\left[\left[\left.\frac{\partial W_{n}\left(x_{n}, t\right)}{\partial x_{n}}\right|_{x_{n}=l}\right]^{2}-\beta^{2}\right]
\end{aligned}
$$

oraz: 


$$
\begin{gathered}
\beta=\frac{W_{n}(l, t)-\left.\left(r-l_{0}\right) \frac{\partial W_{n}\left(x_{n}, t\right)}{\partial x_{n}}\right|_{x_{n}=l}}{R-r} \\
W_{0}=W_{n}(l, t)-\left.\left(r-l_{0}\right) \frac{\partial W_{n}\left(x_{n}, t\right)}{\partial x_{n}}\right|_{x_{n}=l} \\
\varphi=\frac{\left.\left(R-l_{0}\right) \frac{\partial W_{n}\left(x_{n}, t\right)}{\partial x_{n}}\right|_{x_{n}=l}-W_{n}(l, t)}{R-r}
\end{gathered}
$$

Całkowita energia kinetyczna $T$ jest sumą energii kinetycznych masy skupionej $T_{2}$ oraz poszczególnych segmentów układu $T_{1}$ :

$$
\begin{aligned}
& T_{1}=\frac{1}{2} \sum_{i=1}^{n}(\rho A)_{i} \int_{0}^{l}\left[\frac{\partial W_{i}\left(x_{i}, t\right)}{\partial t}\right]^{2} d x_{i} \\
& T_{2}=\frac{1}{2} m\left[\frac{\partial W_{n}(l, t)}{\partial t}\right]^{2}
\end{aligned}
$$

Zagadnienie brzegowe drgań analizowanego układu smukłego sformułowano w oparciu o zasadę Hamiltona:

$$
\delta \int_{t_{1}}^{t_{2}}(T-V) d t=0
$$

gdzie: $t_{1}, t_{2}-$ współrzędne czasu, $\delta$ - operator wariacji.

Po obliczeniu wariacji poszczególnych składowych energii mechanicznej i podstawieniu ich do równania (11), przy jednoczesnym uwzględnieniu geometrycznych warunków brzegowych oraz geometrycznych warunków ciągłości:

$$
\begin{aligned}
& W_{1}(0, t)=0,\left.\frac{\partial W_{1}\left(x_{1}, t\right)}{\partial x_{1}}\right|_{x_{1}=0}=0 \\
& W_{j}(l, t)=W_{j+1}(0, t)
\end{aligned}
$$




$$
\left.\frac{\partial W_{j}\left(x_{j}, t\right)}{\partial x_{j}}\right|_{x_{j}=l}=\left.\frac{\partial W_{j+1}\left(x_{j+1}, t\right)}{\partial x_{j+1}}\right|_{x_{j+1}=0}, \quad j=1,2, \ldots, n-1
$$

otrzymano:

- różniczkowe równania ruchu w kierunku poprzecznym do osi układu

$$
(E J)_{i} \frac{\partial^{4} W_{i}\left(x_{i}, t\right)}{\partial x_{i}^{4}}+P \frac{\partial^{2} W_{i}\left(x_{i}, t\right)}{\partial x_{i}^{2}}+\rho A \frac{\partial^{2} W_{i}\left(x_{i}, t\right)}{\partial t^{2}}=0, i=1,2, \ldots, n
$$

- naturalne warunki brzegowe na swobodnym końcu układu

$$
\begin{aligned}
& \left.(E J)_{n} \frac{\partial^{2} W_{n}\left(x_{n}, t\right)}{\partial x_{n}{ }^{2}}\right|_{x_{n}=l}+P\left[\left.\rho \frac{\partial W_{n}\left(x_{n}, t\right)}{\partial x_{n}}\right|_{x_{n}=l}+v W_{n}(l, t)\right]=0 \\
& \left.(E J)_{n} \frac{\partial^{3} W_{n}\left(x_{n}, t\right)}{\partial x_{n}{ }^{3}}\right|_{x_{n}=l}+P\left[\left.\eta \frac{\partial W_{n}\left(x_{n}, t\right)}{\partial x_{n}}\right|_{x_{n}=l}+\gamma W_{n}(l, t)\right]+ \\
& -m \frac{\partial^{2} W_{n}(l, t)}{\partial t^{2}}=0
\end{aligned}
$$

gdzie parametry $\rho, v, \eta, \gamma$ określają zależności pomiędzy promieniami głowic wymuszającej $R$ i przejmującej obciążenie $r$ oraz długością $l_{0}$ sztywnego elementu (rygla):

$$
\rho=\frac{\left(r-l_{0}\right)\left(R-l_{0}\right)}{R-r}, \quad v=-\frac{r-l_{0}}{R-r}, \quad \eta=\frac{R-l_{0}}{R-r}, \quad \gamma=-\frac{1}{R-r}
$$

- naturalne warunki ciągłości pomiędzy poszczególnymi segmentami kolumny

$$
\begin{aligned}
& \left.(E J)_{j} \frac{\partial^{2} W_{j}\left(x_{j}, t\right)}{\partial x_{j}^{2}}\right|_{x_{j}=l}=\left.(E J)_{j+1} \frac{\partial^{2} W_{j+1}\left(x_{j+1}, t\right)}{\partial x_{j+1}^{2}}\right|_{x_{j+1}=0} \\
& \left.(E J)_{j} \frac{\partial^{3} W_{j}\left(x_{j}, t\right)}{\partial x_{j}^{3}}\right|_{x_{j}=l}=\left.(E J)_{j+1} \frac{\partial^{3} W_{j+1}\left(x_{j+1}, t\right)}{\partial x_{j+1}^{3}}\right|_{x_{j+1}=0}, j=1,2, \ldots, n-1
\end{aligned}
$$


Warunki ciągłości dotyczące równości: przemieszczeń poprzecznych (14), kątów ugięć (15), sił poprzecznych (23) oraz momentów gnących (24) pomiędzy poszczególnymi segmentami rozważanej w pracy kolumny zapisano dla punktów leżących na osi symetrii układu. Biorąc pod uwagę rzeczywisty kształt badanego układu smukłego, w tym nieznaczny gradient zmian wymiaru poprzecznego wzdłuż osi kolumny założono poprawność równań dynamiki na całej długości kolumny, w tym również w strefie brzegowej.

Takie zdefiniowanie naturalnych warunków brzegowych układu poddanego działaniu obciążenia uogólnionego $\mathrm{z}$ siłą skierowaną do bieguna dodatniego umożliwia poprzez odpowiedni dobór wartości wymienionych współczynników uzyskanie innych przypadków obciążenia konserwatywnego.

\section{Wyniki analizy numerycznej}

Biorąc pod uwagę rozwiązanie różniczkowych równań ruchu (16) i geometryczne i naturalne warunki brzegowe $(12-13,17-18)$ oraz warunki ciągłości (14-15, 19-20) opracowano algorytmy do analizy numerycznej drgań poprzecznych rozpatrywanej kolumny. Wyniki obliczeń zaprezentowano w postaci bezwymiarowej, wprowadzając następujące parametry służące do opisu układu:

- parametry określające geometrię układu

$$
Z^{*}=\frac{b_{1}-b_{n}}{L} \cdot 100 \%, \quad p^{*}=\frac{p}{L}, \quad q^{*}=\frac{q}{L}
$$

- parametry opisujące geometrię struktury realizującej obciążenie

$$
R^{*}=\frac{R-l_{0}}{L}, \quad \Delta r=\frac{R-r}{L},
$$

- parametry obciążenia zewnętrznego oraz obciążenia krytycznego

$$
\lambda=\frac{P L^{2}}{(E J)_{p r}}, \quad \lambda_{c}=\frac{P_{c} L^{2}}{(E J)_{p r}}
$$

- bezwymiarowy parametr drgań

$$
\Omega=\frac{\omega^{2}(\rho A)_{p r} L^{4}}{(E J)_{p r}}
$$

Wartości z indeksami „pr" we wzorach (30-32) odnoszą się do układu porównawczego - kolumny pryzmatycznej (o stałym przekroju poprzecznym) o takiej samej objętości, co kolumna niepryzmatyczna. 


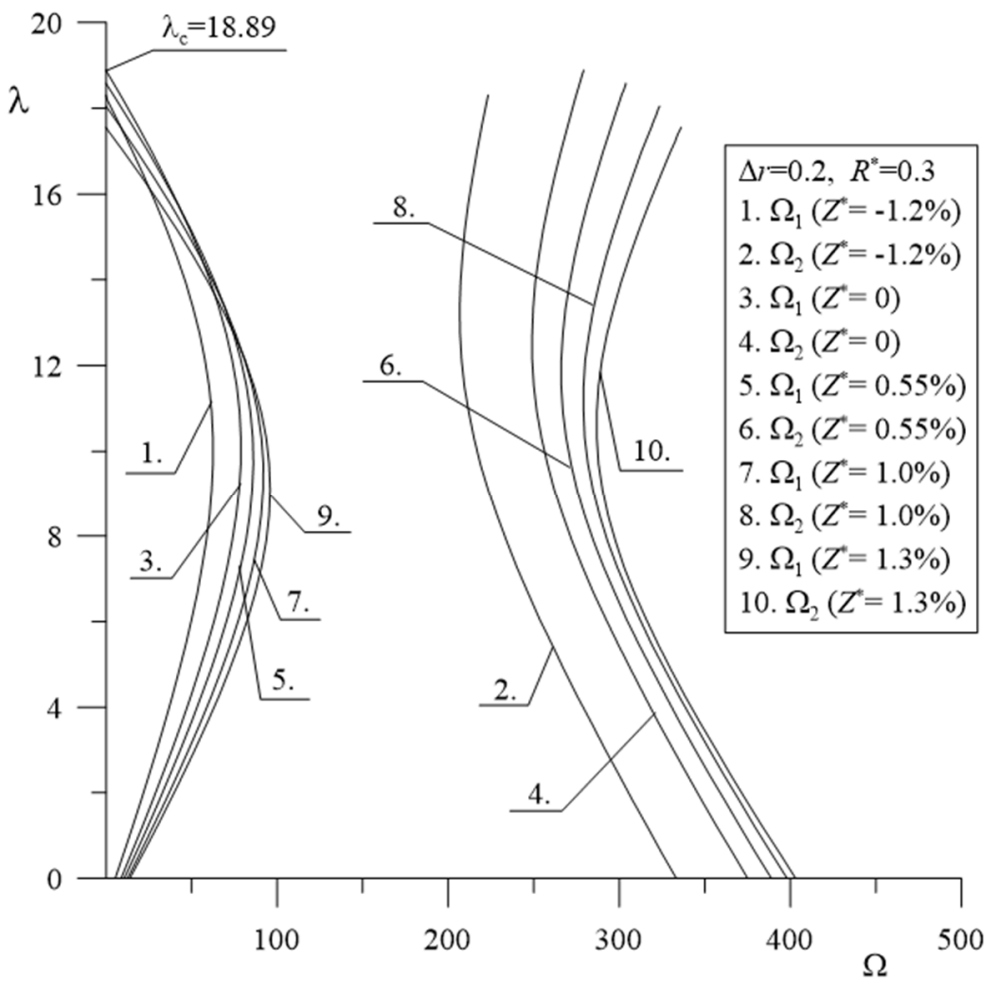

Rys. 2. Zmiana pierwszych dwóch częstości drgań kolumny niepryzmatycznej aproksymowanej funkcja liniową $w$ funkcji obciążenia zewnętrznego przy wybranych wartościach parametrów struktury realizującej obciążenie oraz zbieżności układu $Z^{*}$

Fig. 2. The change in the two first frequencies of the vibration of the nonprismatic column approximated by the linear function in relation to the external load for selected values of the parameters of the loading structure as well as the taper ratio $Z^{*}$

Na rysunkach 2-3 przedstawiono zmianę dwóch pierwszych częstości drgań własnych układu o zmiennym przekroju poprzecznym w funkcji obciążenia zewnętrznego. W początkowym zakresie obciążenia wraz ze wzrostem parametru $\mathrm{Z}^{*}$ (przy aproksymacji zarysu kolumny funkcją liniową) oraz parametru $q^{*}$ (opisującego położenie współrzędnej wierzchołka paraboli) rośnie częstość drgań własnych. Przy dalszym wzroście obciążenia zewnętrznego wartość częstości może rosnąć lub maleć, w zależności od wartości parametrów opisujących geometrię kolumny. Wartość obciążenia zewnętrznego, przy którym częstość drgań własnych równa jest zero odpowiada obciążeniu krytycznemu układu. Na wykresach zaznaczono również maksymalne wartości parametru obciążenia krytycznego. W przypadku aproksymacji kształtu funkcją liniową (rys. 2.) największe obciążenie krytyczne odnotowano przy zbieżności układu $Z^{*}$ równej zero (układ pryzmatyczny). W przypadku opisu zarysu kolumny funkcją kwadratową, 
przy zadanych parametrach głowic $R^{*}$ i $\Delta r$ oraz parametrze $p^{*}$, najkorzystniejszy ze względu na wartość obciążenia krytycznego jest kształt zdefiniowany przy $q^{*}=0.55$. Biorąc pod uwagę nachylenie krzywych w zależności od wartości obciążenia krytycznego, układ zalicza się do układów typu dywergencyjnego pseudoflatterowego.

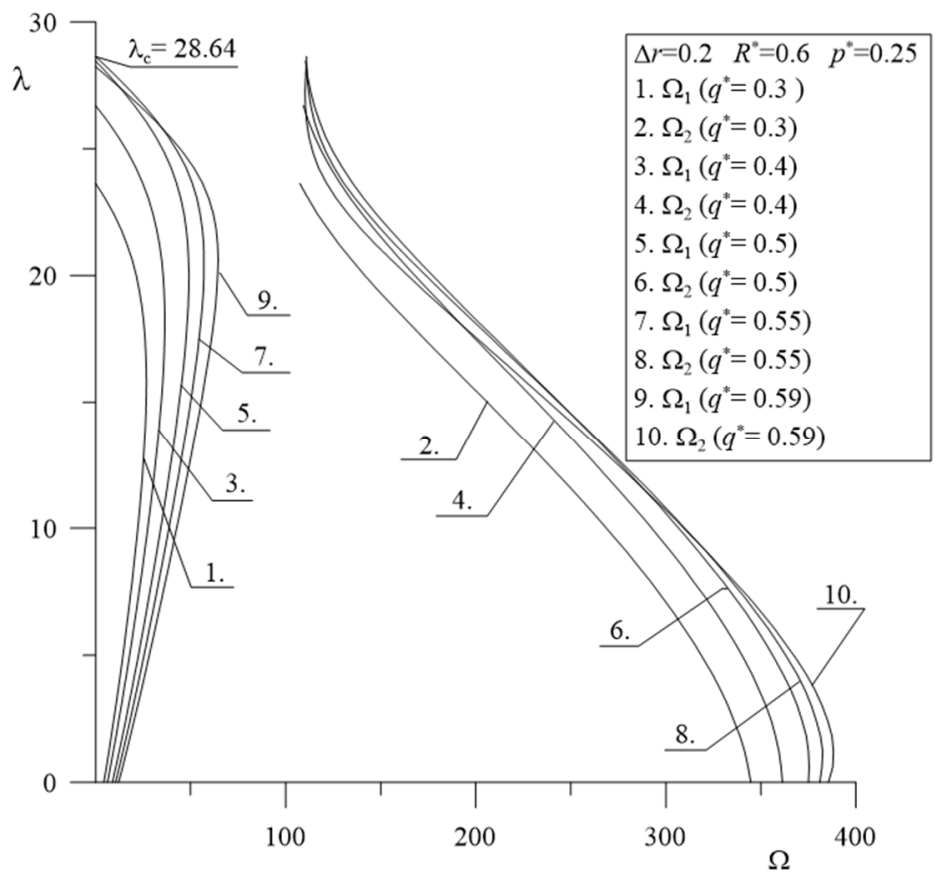

Rys. 3. Krzywe charakterystyczne układu o zarysie aproksymowanym funkcją paraboliczną przy zadanej geometrii struktury obciążającej oraz wybranych wartościach parametru $q^{*}$

Fig. 3. Characteristic curves of the system of the shape approximated by the parabolic function at a given geometry of the loading structure and selected values of the parameter $q^{*}$

Rysunek 4. przedstawia przebiegi dwóch pierwszych częstości drgań własnych analizowanego układu aproksymowanego wielomianem drugiego stopnia w funkcji parametru obciążenia zewnętrznego przy wybranych wartościach parametru promienia głowicy wywołującej obciążenie. Przy dowolnie określonym kształcie układu oraz geometrii struktury realizującej obciążenie zewnętrzne istnieje taka wartość parametru $R^{*}$, w przypadku której wartość obciążenia kry- 
tycznego kolumny jest największa. Zależność ta potwierdza się również w przypadku układów o kształcie opisanym dowolną funkcją liniową.

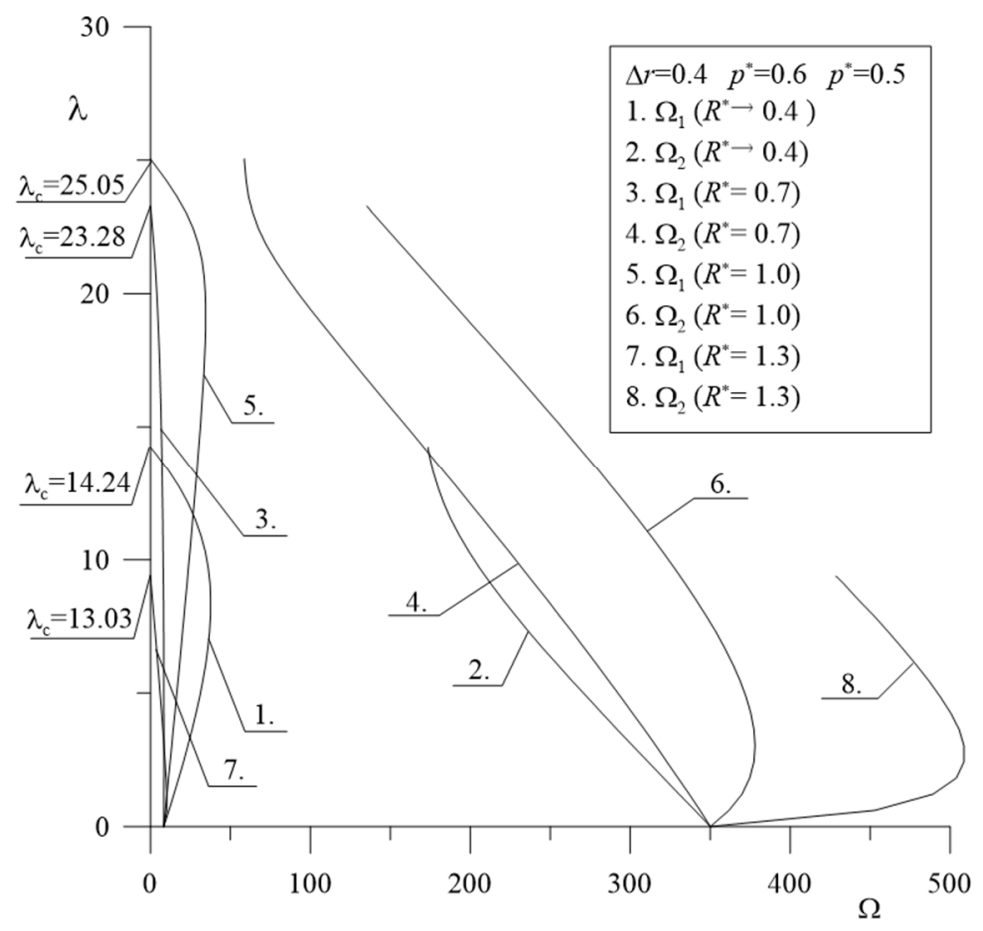

Rys. 4. Krzywe na płaszczyźnie obciążenie zewnętrzne - częstość drgań własnych układu aproksymowanego wielomianem drugiego stopnia przy zadanej geometrii kolumny oraz zmiennych wartościach promienia głowicy wywołującej obciążenie

Fig. 4. Curves on the plane external load - frequency of the free vibration of the system of the shape approximated by the polynomial of degree 2 for known geometry of the column and variable values of the radius of the loading head

\section{Wnioski}

W pracy analizie drgań swobodnych poddano kolumnę niepryzmatyczną przy obciążeniu uogólnionym z siłą skierowaną do bieguna dodatniego. Na podstawie przeprowadzonych obliczeń numerycznych sformułowano następujące wnioski:

- biorąc pod uwagę, iż warunki ciągłości są zdefiniowane na osi symetrii rozważanej kolumny założono, że w otoczeniu tych punktów spełniona jest zasa- 
da de Saint - Venanta. W pracy nie uwzględniono wpływu spiętrzenia naprężeń w warstwie brzegowej,

- aproksymacja kształtu układu wpływa na wartość częstości drgań, w zależności od parametrów opisujących zarys układu oraz wartości obciążenia zewnętrznego, zmiana kształtu kolumny może powodować wzrost bądź spadek wartości częstości drgań własnych,

- wartość obciążenia krytycznego odpowiadająca zerowej wartości podstawowej częstości drgań własnych układu zależy w głównej mierze od wartości parametrów opisujących jego kształt oraz parametrów geometrycznych struktury obciążającej. Otrzymane na podstawie kinetycznego kryterium utraty stateczności siły krytyczne znajdują odzwierciedlenie w wynikach analiz numerycznych rozpatrywanego układu przeprowadzonych w oparciu o statyczne kryterium utraty stateczności,

- rozważany w pracy układ można zaliczyć w zależności od wartości parametrów opisujących strukturę realizującą obciążenie do typu dywergencyjnego lub dywergencyjnego pseudoflatterowego,

- aproksymacja kształtu kolumny ograniczona jest warunkiem, według którego wartość szerokości $b$ segmentów kolumny musi być większa bądź równa grubości $h$ tego segmentu.

\section{Literatura}

[1] W. Sochacki: The dynamic stability of a stepped cantilever beam with attachments, Journal of Vibroengineering, Vol. 15 Issue 1, 2013, pp. 280-290.

[2] J. Szmidla, M. Kluba: Stateczność i drgania swobodne niepryzmatycznego układu smukłego poddanego obciążeniu eulerowskiemu, Modelowanie Inżynierskie, 41, 2011, str. 385-394.

[3] A. P. Seyranian, E. Lund, N. Olhoff, Multiple eigenvalues in structural optimization problems, Struct. Optimization, 8, 1994, pp. 207-227.

[4] Demirdag O., Yesilce Y.: Solution of free vibration equation of elastically supported Timoshenko columns with a tip mass by differential transform method, Journal of Advances in Engineering Software, vol. 42 (10), 2011, pp. 860-867.

[5] S. Kukla: Free vibrations and stability of stepped columns with cracks, Journal of Sound and Vibration, Vol. 319 (3-5), 2009, pp. 1301-1311.

[6] E. Esmailzadeh, A. R. Ohadi: Vibration and stability analysis of non-uniform Timoshenko beam under axial and distributed tangential loads, Journal of Sound and Vibration, Vol. 236 (3), 2000, pp. 443-456.

[7] J. T. Katsikadelis, G. C. Tsiatas: Non-linear dynamic stability of damped Beck's column with variable cross-section, International Journal of Non-Linear Mechanics, 42, 2007, pp. 164-171.

[8] Q. Mao: Free Vibration analysis of multiple-stepped beams by using Adomian decomposition method, Mathematical and Computer Modelling, 54, 2011, pp. 756-764. 
[9] L. Tomski, J. Szmidla: Drgania swobodne i stateczność kolumn poddanych obciążeniu swoistemu - sztywne węzły konstrukcyjne układu wymuszającego i przejmującego obciążenie, rozdz. 3. [w] Drgania i stateczność układów smukłych. Praca zbiorowa wykonana pod kierunkiem naukowym i redakcją Lecha Tomskiego, Wydawnictwa Naukowo - Techniczne, Fundacja „Książka Naukowo - Techniczna”, Warszawa 2004, str. 68-133.

[10] S. Uzny: Free Vibrations of an Elastically Supported Geometrically Nonlinear Column Subjected to a Generalized Load with a Force Directed towards the Positive Pole, Journal of Engineering Mechanics, 2011, 137 (11).

\section{FREE VIBRATION ANALYSIS OF THE SLENDER COLUMN OF VARIABLE CROSS - SECTION UNDER THE GENERALIZED LOAD WITH A FORCE DIRECTED TOWARDS THE POSITIVE POLE}

\section{S u m m a r y}

The results of the theoretical considerations and numerical analysis of the issue of the free vibration of the slender system of the variable cross-section under selected case of the specific load were included in this work. Analyzed generalized load with a force directed towards the positive pole is realized by the structure built of heads of the circular outlines: loading and receiving heads. In order to model the variable cross-section of the column, the system was divided into $n$ prismatic segments of the equal length and thickness and the variable width described by the linear function and the polynomial of degree 2, fulfilling the condition of the constant total volume. On the basis of the physical model of the system, the mechanical energy of the structure was defined. The issue of the free vibration was formulated taking into account the Hamilton's principle (energetic method, kinetic criterion of the stability loss). Taking into consideration the geometric boundary conditions and the geometric continuity conditions, the differential equations of motion of particular segments of the column as well as the natural boundary condition and the natural continuity conditions were determined. On the basis of so-defined mathematical model, the computation algorithms enabling numerical examination of the transverse vibration of the column were developed. Within the scope of the carried-out calculations, the range of the changes in the frequency of the free vibration as a function of the external load was determined. An influence of the variable geometric parameters of the column on the value of the natural frequency and the type of the system was discussed, including the parameters describing the shape of the column as well as the geometry of the loading structure.

Keywords: slender systems, free vibrations, specific load, critical load

Przestano do redakcji: $15.02 .2017 \mathrm{r}$.

Przyjęto do druku: 28.04.2017 r. 